\section{Flap Tubing And Waltzing For Complex Facial Reconstruction In The West Indies}

Guelmo Daisley E. ${ }^{1}$, Mohammed F. ${ }^{1}$, Gill P. ${ }^{1}$, Mitchell K. ${ }^{1}$, Lourenco K. ${ }^{1}$, Romany S. ${ }^{1}$

\author{
Affiliations: \\ ${ }^{1}$ Department of Surgery, Port- Of- Spain General \\ Hospital, Trinidad
}

\section{Correspondence:}

Dr. E. Guelmo- Daisley

Department of Surgery,

Port- Of- Spain General Hospital,

Port- Of- Spain,

Trinidad.

Email: egdmed54@gmail.com

DOI: $\underline{\text { doi.org/10.48107/CMJ.2021.03.003 }}$

Copyright: This is an open-access article under the terms of the Creative Commons Attribution License which permits use, distribution, and reproduction in any medium, provided the original work is properly cited.

(C)2021 The Authors. Caribbean Medical Journal published by Trinidad \& Tobago Medical Association.

\section{ABSTRACT}

Ballistic facial wounds present daunting reconstructive challenges to the most experienced of surgeons. The early Waltzing method of tissue transfer, perfected by Sir Gillies, was superseded by free flaps and facial transplantation as methods for facial reconstruction. In the low resource setting however, the Waltz may be the only suitable option. This case study describes the use of the Waltz for facial reconstruction at the Port of Spain General Hospital in Trinidad. The subject sustained a gunshot wound to the face resulting in complex midface and_mandibular defects. Here, bilateral deltopectoral flaps were used to replace destroyed soft tissue (Fig 1).

\section{INTRODUCTION}

The combination of high powered weaponry and trench warfare at the beginning of the twentieth century produced a multitude of complex facial injuries for which there were no acceptable surgical remedies. It was during these dark times, plastic surgery blossomed.

Sir Harold Gillies, a veteran and the father of modern day plastic surgery, perfected the use of the Waltzing method of tissue transfer to treat the functional and aesthetic complications of these nouvelle injuries. The method was named after the Viennese Waltz, where participants are elegantly propelled across a ballroom floor. Similarly, tissue can be 'waltzed' across the body in a number of steps. The Waltz remained popular until the 1970 s when the use of free flap tissue transfer came into vogue and became the method of choice. ${ }^{1}$ However, there are instances where this may not be possible, and the Waltz becomes the most feasible option once more. This case study describes the use of the Waltz for facial reconstruction in a low resource setting, at the Port-ofSpain General Hospital in Trinidad and Tobago.

\section{Case Presentation}

This case is of a 47year old male who presented with a shotgun wound to the face. The point of entry was the right submental region. The injuries sustained include loss of approximately $50 \%$ of the right hemi-mandible, loss of more than $50 \%$ of the maxilla, almost complete loss of dentition, loss of the philtrum, nose, right upper 
lip, right cheek and partial loss of the tongue. In summary, our patient sustained a Corderio and Santamaria type IIIa midface defect and Schultz type I mandibular defect. ${ }^{2,3}$ The initial plan of action involved use of either a fibular osseocutaneous free flap or an anterolateral thigh flap. However, there were unforeseen difficulties in acquiring all the appropriate equipment required. He subsequently had mandibular reconstruction, but repair of the maxilla was not possible as the appropriate plates were not obtained. Furthermore, microvascular sutures were not available and transfer of the patient to a better equipped facility abroad was not an option. The alternative involved using the Waltz in a multi-staged reconstruction of the face (Fig 2).

The reconstruction proceeded as follows:

1. Elevation and delay ${ }^{5}$ of bilateral extended deltopectoral flaps for 6 weeks.

2. Re-elevation and tubing of flaps with inset of distal ends into the region of the nasolabial folds (first 'step' of the Waltz). The flaps were now connected to the patient at both ends; at the shoulder proximally and at the nasolabial folds distally for 6 weeks. This period allowed the flap to establish a shared blood supply with the recipient site (the face). The donor sites were closed via primary approximation and split thickness skin grafts.

3. Disconnection of tubed flaps from the chest after tourniquet tests showed back flow perfusion from the nasolabial site (third stage of reconstruction). The flaps were then allowed to hang freely for a period of rest to test the resilience of the blood supply from the face.

4. Necrosis of the free end of the right side tube (one third) was noted and debrided. The fourth stage involved two parts. Firstly, the splayed free end of the right flap and the remnant of the upper lip were approximated. Similarly, the splayed free end of the left flap was used to close the defect involving the midface nasal region. Therefore, both flaps were essentially hugging the face, again attached at two points (second 'step' of the Waltz).

5. The fifth stage involved re- fashioning an upper lip using the right deltopectoral flap. The redundant tissue was used to close the defect at the nasolabial fold.

The final stage involved repurposing the left flap to create a 'nose' consisting of a single nare. The redundant tissue was used to close the area around the nasolabial fold.

\section{Fig 1. Patient at presentation and at latest procedure}

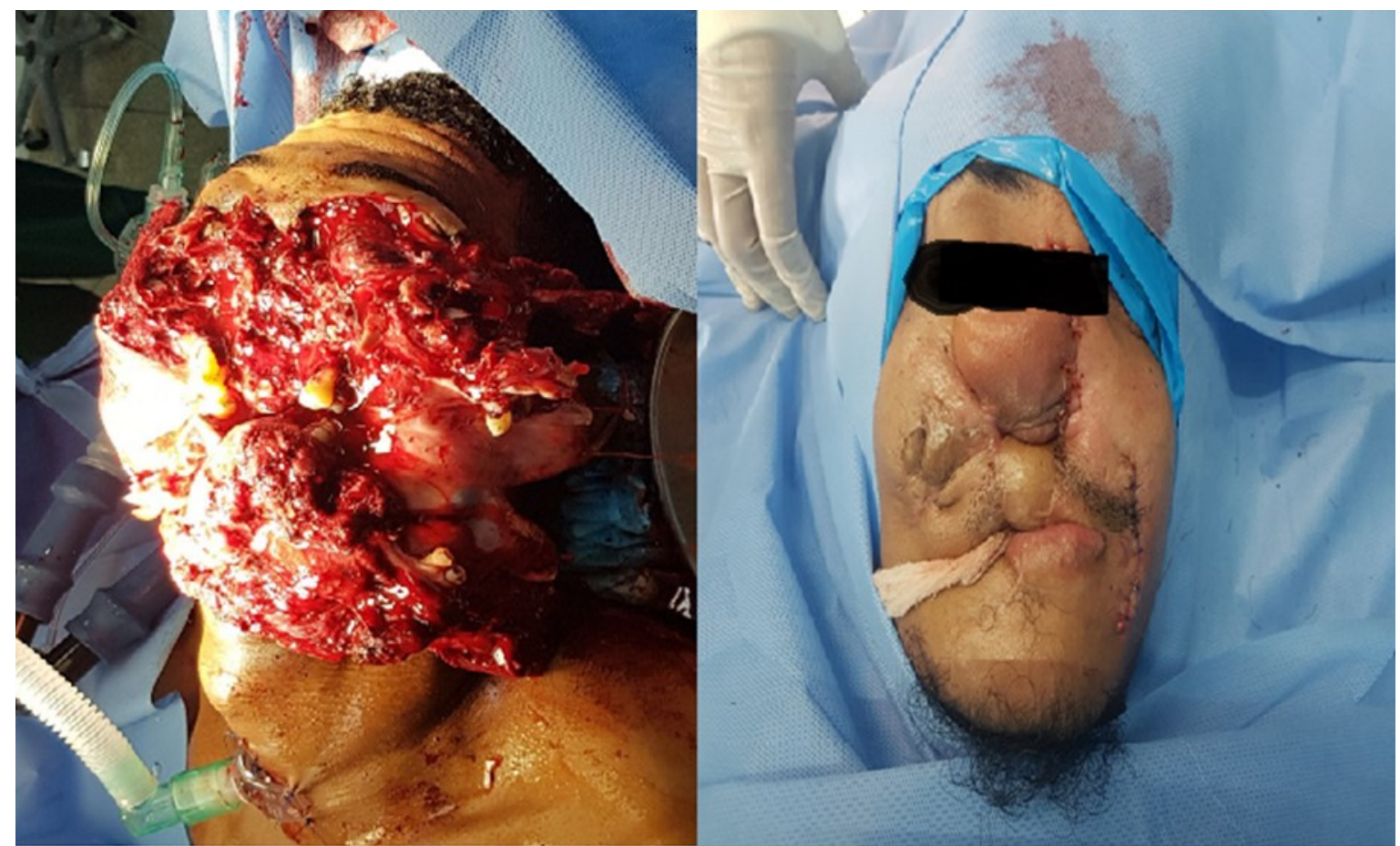




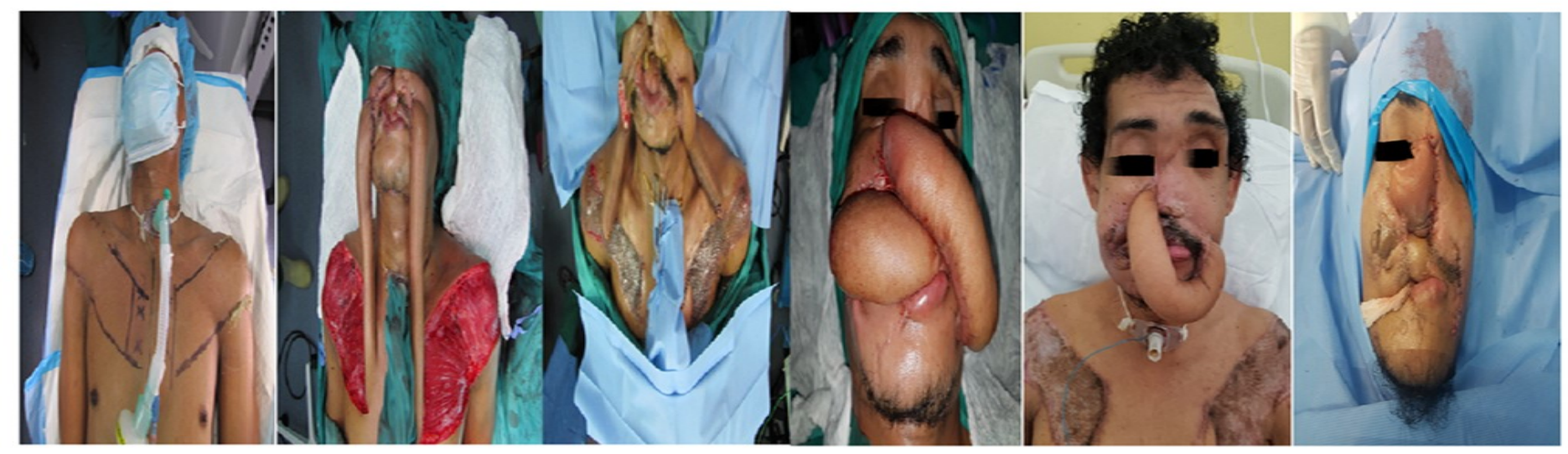

\section{DISCUSSION}

The Port- Of- Spain General hospital, one of the largest trauma centres in our country, offers all surgical services albeit in a low resource setting.

Our patient sustained a complex mid and lower face injury. In order to clarify the type of injury sustained the maxilla is divided into thirds: lower, middle and upper. ${ }^{5}$ The lower one third comprises the palatal arches and separates the nasal cavity and maxillary sinuses from the oral cavity. The middle third comprises the outer walls of the maxillary sinuses and the nasal cavity. The upper third separates the maxillary sinuses from the orbital cavity. According to the Corderio and Santamaria classification of complex midface defects, our patient was found to have a type IIIa defect. ${ }^{2}$ This means that even the upper one third of the maxilla was compromised (the orbital floor was broken). His eyes and vision were spared. However, his speech and ability to chew and swallow were impaired. Our patient also sustained a Schultz type I mandibular defect. ${ }^{3}$ This is a unilateral dentoalveolar defect not crossing the midline nor extending beyond the angle of the mandible.

The use of microvascular free flaps is the gold standard of facial reconstruction today, with success rates ranging between $95-98 \% .{ }^{6}$ Tissues used may be harvested from the anterolateral thigh, the radial forearm, the fibular region, the latissimus dorsi, the scapular or the abdominal regions.

The anterolateral thigh (ALT) flap is versatile, can be used for composite tissue replacement and has the potential to be sensate. It has a long pedicle and provides coverage for large defects with minimal donor site morbidity. Success rates range between $95-98 \%{ }^{7}$ However, there may be skin colouration mismatch and hair growth.

The fibular osseocutaneous flap may consist of thick bicortical bone which allows for the placement of osseointegrated implants. It may be easily raised, has a long pedicle consisting of large calibre vessels, provides ample bone length and the bone is sufficiently vascularised to tolerate segmental osteotomies to enable appropriate contouring. ${ }^{8}$

The Latissimus Dorsi and abdominal flaps may prove to be too bulky for facial reconstruction. The scapula flap has an osseous component but may be difficult to orient and has a short pedicle. The radial forearm may not be suitable to cover large defects.

The financial constraints of our hospital limited our ability to provide the gold standard of care. This ideal management in this situation would have included reconstruction of soft-tissues of the upper lips, bony and soft-tissue platform of the mid-face and osseo-integrated pins to accommodate a nasal/midface prosthesis. ${ }^{9}$ Unable to do so, we chose to employ the use of pedicled flaps and the Waltzing method for reconstruction. The waltzing method is used in difficult reconstructive cases where closure of a complex wound may not be possible in a single step. Here, we utilized bilateral deltopectoral flaps. The deltopectoral flap is the workhorse of head and neck reconstruction. This flap proved to be ideal as it is soft and pliable, and quickly raised and inset into its destination leading to shorter operative times. The donor site can be closed primarily or using a split thickness skin graft. Success rates range between $70-90 \%$. The use of pedicled flaps however, may be limited via the length of 
the pedicle or the geometry of the flap and oftentimes leaves the patient with both cosmetic and functional defects.

The length of the procedure, the materials used, the number of surgeons required and the length of time spent in hospital, all contribute to the cost of a procedure. It is generally accepted that the cost of pedicled flap reconstruction is much lower than the cost of microvascular free flap reconstruction which requires on average longer operating times, use of expensive equipment and materials and requires more surgeons or manpower.

Despite the complication of necrosis of the lower one third of the right tubed flap, there was sufficient tissue for reconstruction. This may have been the result of venous congestion at the proximal end of the flap due to dependant oedema. Consideration of elevation of this type of flap in future may assist in its prevention. The necrotic tissue was allowed to establish its extent prior to debridement to healthy, well perfused tissue. The use of the intermittent tourniquet technique may also help to boost the blood supply. ${ }^{10}$ It involves the application of a tourniquet at the proximal end near the pedicle after the flap had been inset at the recipient site for at least 5 days. The tourniquet is then gradually tightened over a period of days which gradually introduces tissue ischaemia which stimulates the development of a stronger vascular supply. As highlighted in the "delay" phenomenon theory, tissue ischaemia is a strong stimulator of angiogenesis.

Our efforts proved to be fruitful as we were able to achieve some of our initial reconstructive goals. The patient is now able to eat and there was elimination of salivary drooling. With the recreation of the lips, our patient's ability to communicate with others has improved. His reconstructive journey is still in evolution however. Further milestones awaiting fruition include:

1. Bony reconstruction of the midface either via prosthesis or bone grafting or both. This will allow separation of the oral and nasal cavities and separation of the orbital and oral cavities.

2. Refinement of his nasal reconstruction by thinning of the already-created nasal mound, addition of structural support using autologous rib cartilage and creation of the nares.

\section{DECLARATION}

Ethical Approval Statement: Ethical approval for this endeavour beyond the patient's consent was not required.

\section{Conflict of interest: None}

Informed Consent: The authors of this paper would like to declare that permission for the use of clinical information and images were obtained from the patient in the form of written consent. The patient is aware that all identifying information will be withheld to maintain anonymity.

\section{Funding: None}

\section{REFERENCES}

1. Marck K, Bamji A, et al. The tubed pedicle flap centennial: Its concept, origin, rise and fall. European Journal of plastic surgery 2017;40: 473-478.

2. Corderio PG, Santamaria EA. Classification system and algorithm for reconstruction of maxillectomy and midfacial defects. Plastic and Reconstructive Surgery 2000; 105: 2331-2346.

3. Schultz BD et al. Classification of mandible defects and algorithm for microvascular reconstruction. Plastic and Reconstructive Surgery 2015;135(4): 743e-754e.

4. Hamilton K, Wolfswinkel EM, Weathers WM, et al. The Delay Phenomenon: A compliation of knowledge across specialties. Craniomaxillofacial Trauma \& Recostruction 2014; 7(2): 112-118.

5. Ozkan O, Coskunfirrat OK, et al. Midface Reconstruction. Seminars in Plastic Surgery 2010; 24 (2):181-187.

6. Cheng-Chun W, Pao-Yuan L, Khong- Yik C, Yur- Ren K. Free tissue transfers in head and neck reconstruction: complications, outcomes and strategies for management of flap failure: analysis of 2019 flaps in single institute. Microsurgery 2013;34(5): https://doi.org/10.1002/ micr.22212

7. Khadakban D, Kudpaje A, Iyer S. Reconstructive indications of anterolateral thigh free flaps in head and 
neck reconstruction. Craniomaxillofacial Trauma and Reconstruction 2016; 9(1):40-45.

8. Shroff SS, Nair SC, Kumar B. Versatility of the fibular free flap in reconstruction of facial defects: a centre study. Journal Of Maxillofacial and Oral Surgery 2017;16 (1):101-107.

9. Federspil PA. Implant retained craniofacial prosthesis for facial defects. GMS Current Topics in Otorhinolaryngology Head and Neck Surgery 2009;

8:Doc3: https://doi.10.3205/cto000055

10. George A, Cunha- Gomes D, Thatte RL. Early division of pedicled flaps using a simple device: a new technique. British Journal Of Plastic Surgery 1996; 49:119-122. 